\title{
Conduction Through Viscoelastic Phase in a Redox-Active Ionic Liquid at Reduced Temperatures
}

\author{
Verner K. Thorsmølle,* Daniel Topgaard, Jan C. Brauer, Shaik M. Zakeeruddin, \\ Björn Lindman, Michael Grätzel, and Jacques-E. Moser
}

Salts in the liquid phase at room temperature-ionic liquidshave recently received increased attention due to their unique properties. ${ }^{[1]}$ These include high ionic conductivity, high thermal and chemical stability, broad electrochemical windows, non-volatility and non-flammability. These important properties make them versatile alternatives to conventional solvent-based systems, and their potential applications range from electrolytes in solar cells, ${ }^{[2]}$ fuel cells, ${ }^{[3]}$ supercapacitors and batteries, ${ }^{[4]}$ lubricants and heat-transfer fluids, ${ }^{\left[{ }^{[}\right]}$solvents for clean chemical synthesis and catalysis ${ }^{[6]}$ to solvents for cellulose. ${ }^{[7]}$

Iodine addition to iodide-based ionic liquids leads to extraordinarily efficient charge transport, vastly exceeding that expected for such viscous systems. ${ }^{[8-12]}$ The origin of this anomalously high charge transport in $\mathrm{I}^{-} / \mathrm{I}_{3}{ }^{-}$anion containing melts has been attributed to Grotthuss conduction via the exchange reaction $\mathrm{I}^{-}+\mathrm{I}_{3}{ }^{-} \leftrightarrows \mathrm{I}_{3}{ }^{-}+\mathrm{I}^{-} .^{[1]}$ The displacement of $\mathrm{I}^{-}$and $\mathrm{I}_{3}{ }^{-}$ through this bond-exchange reaction leads to effective charge transfer without mass displacement. In addition, the conductivity increases abruptly by an order of magnitude at the point where higher polyiodides become important in the redox active ionic liquid 1-methyl-3-propylimidazolium iodide (PMII) as a function of increasing analytical iodine $\left(\mathrm{I}_{2}\right)$ concentration $\left[\mathrm{I}_{2}\right]_{\mathrm{a}}{ }^{[1]}$ (The calculated analytical $\mathrm{I}_{2}$ concentration $\left[\mathrm{I}_{2}\right]_{\mathrm{a}}$ takes into account the volume increase when the neutral $\mathrm{I}_{2}$ is added to the charged PMII melts). ${ }^{[1]}$ This increase in conductivity has been attributed to bond-exchange processes among the higher polyiodides, $\mathrm{I}_{5}^{-}, \mathrm{I}_{7}^{-}$, etc. ${ }^{[1]}$ PMII is the benchmark of the iodide salts that form room temperature ionic liquids, characterized by a relatively low viscosity, and has therefore been the candidate of choice for binary ionic liquids in the solvent-free dye-sensitized Grätzel solar cell $\left(\left[\mathrm{I}_{2}\right]_{\mathrm{a}} \sim 0.2 \mathrm{M}\right) \cdot{ }^{[2,13]}$

\footnotetext{
Dr. V. K. Thorsmølle, J. C. Brauer, Dr. S. M. Zakeeruddin,

Prof. M. Grätzel, Prof. J.-E. Moser

Institute of Chemical Sciences and Engineering

École Polytechnique Fédérale de Lausanne

Station 6, CH-1015 Lausanne, Switzerland

E-mail: verner.thorsmolle@epfl.ch

Prof. D. Topgaard, Prof. B. Lindman Department of Physical Chemistry 1

Lund University

SE-22100 Lund, Sweden

Prof. B. Lindman

Departamento de Quimica

Universidade de Coimbra Rua Larga

3004-535-Coimbra, Portugal
}

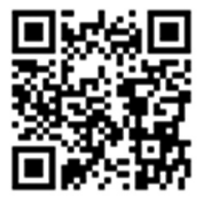

DOI: $10.1002 / \mathrm{adma} .201104230$
The conductivity of PMII melts at room temperature is known to be determined by Grotthuss bond-exchange processes, physical ionic diffusion as well as ion pairing processes.$^{[1]}$ Here, we investigate the temperature-dependent conductivity behaviour in PMII melts up to the highest $\mathrm{I}_{2}$ concentrations using dc conductivity, nuclear magnetic resonance (NMR) diffusivity, viscosity and differential scanning calometry (DSC) measurements. For iodine concentrations higher than $3.9 \mathrm{M}$, we discovered the formation of a viscoelastic phase upon cooling. Despite of the very high viscosity of such polyiodide-containing PMII melts a strikingly high conductivity is maintained through Grotthuss-type bond exchange and ionic conduction. These novel results are important for the fundamental understanding of conduction in molten salts and for applications where ionic liquids are used as charge-transporting media such as in batteries and dye-sensitized solar cells.

The composition and the physical properties of the melts formed by the addition of $\mathrm{I}_{2}$ to PMII depend on several chemical equilibria as outlined in a previous report. ${ }^{[1]}$ PMII consists of a $\mathrm{PMI}^{+}$cation and an $\mathrm{I}^{-}$anion. Its structure is shown as an inset to Figure 1c. When $\mathrm{I}_{2}$ is added to PMII, triiodide $\left(\mathrm{I}_{3}^{-}\right)$is formed via $\mathrm{I}^{-}+\mathrm{I}_{2} \leftrightarrows \mathrm{I}_{3}{ }^{-}$. At higher $\mathrm{I}_{2}$ concentrations, higher polyiodides, $\mathrm{I}_{5}^{-}, \mathrm{I}_{7}^{-}$, etc. appear via $\mathrm{I}_{3}^{-}+\mathrm{I}_{2} \leftrightarrows \mathrm{I}_{5}^{-}, \mathrm{I}_{5}^{-}+\mathrm{I}_{2} \leftrightarrows$ $\mathrm{I}_{7}^{-}$, etc, ${ }^{[11]}$ where these equilibria are essentially displaced to the right. ${ }^{[11]}$ The Grotthuss conductivity mechanism proceeds via the bond exchange reaction $\mathrm{I}^{-}+\mathrm{I}_{3}{ }^{-} \leftrightarrows \mathrm{I}_{3}{ }^{-}+\mathrm{I}^{-}$, through which the iodide and triiodide ions are displaced without effective mass transfer. ${ }^{[1]}$

In Figure 1 we compare the temperature dependence of the viscosity (a) with that of the dc conductivity (b) of PMII/ $\mathrm{I}_{2}$ melts for various iodine concentrations $\left[\mathrm{I}_{2}\right]_{\mathrm{a}}$. Strikingly, these measurements reveal substantial conduction at temperatures where the viscosity is considerable. Thus, above $\left[\mathrm{I}_{2}\right]_{\mathrm{a}} \sim 3.9 \mathrm{M}$ the viscosity increases dramatically by $\sim 6$ orders of magnitude below an onset temperature $\left(T_{\text {onset }}\right)$, which corresponds to the formation of a viscoelastic phase (see Figure 1a and the Supporting information, Section 2). Viscoelastic properties have recently been reported for ionic liquid composites. ${ }^{[14,15]}$ The formation of a crystalline phase can be excluded unambiguously on the basis of featureless DSC data at corresponding temperatures and the absence of Bragg peaks in X-ray diffraction. Despite the dramatic rise in viscosity for $\left[\mathrm{I}_{2}\right]_{\mathrm{a}}>3.9 \mathrm{M}$, the dc conductivity is unaffected until it drops by many orders of magnitude at significantly lower temperatures. DSC measurements, which will be discussed in Figure 3 below, show that this drop is due to crystallization. Figure 2 shows the temperatures for these two transitions as a function of $\left[\mathrm{I}_{2}\right]_{\mathrm{a}}$, defining the domains of the liquid, viscoelastic and crystalline phases. 




Figure 1. Temperature-dependent measurements of $\mathrm{PMII} / \mathrm{I}_{2}$ mixtures. a) Viscosity versus temperature at various iodine concentrations $\left[I_{2}\right]_{a}$. Inset: Dynamic viscoelastic behaviour of the PMII/I $\mathrm{I}_{2}$ mixture for $\left[\mathrm{I}_{2}\right]_{\mathrm{a}}=$ $4.18 \mathrm{M}$ close to the liquid-viscoelastic transtion. $G^{\prime}$ and $G^{\prime \prime}$ represent the elastic and viscous contributions, respectively. b) dc conductivity versus temperature at various $\left[\mathrm{I}_{2}\right]_{\mathrm{a}}$. C) Diffusivity versus temperature for the cation $\mathrm{PMI}^{+}$measured by NMR.

Like the dc conductivity (Figure 1a), NMR diffusivity measurements of the $\mathrm{PMI}^{+}$species (Figure 1c) are continuous across $T_{\text {onset }}$, despite the conductivity-viscosity anomaly. This points to the formation of a rigid polyiodide structure that permits both Grotthuss and ionic conduction. This structure is established only for $\left[\mathrm{I}_{2}\right]_{\mathrm{a}} \geq 3.9 \mathrm{M}$ corresponding to a rather concentrated PMII system with at least $46 \mathrm{wt} \%$ or $25 \%$ volume fraction of $\mathrm{I}_{2}$ implying a considerably densely-packed porous polyiodide medium, where nevertheless the molecular transport is essentially unaffected across $T_{\text {onset }}$. At $\left[\mathrm{I}_{2}\right]_{\mathrm{a}} \sim 3.9 \mathrm{M}$, the temperature range where the viscoelastic phase exists amounts to $\sim 12 \mathrm{~K}$. At $\left[\mathrm{I}_{2}\right]_{\mathrm{a}} \sim 4.2 \mathrm{M}$, corresponding to a nearly equimolar amount of PMII and iodine $\left(x_{I_{2}} \approx 0.5\right)$, this viscoelastic temperature domain goes through a minimum of $\sim 3 \mathrm{~K}$. This composition coincides with the appearance of a resonance at $2.29 \mathrm{THz}$ in the terahertz conductivity spectrum and a sudden increase in the room temperature dc conductivity, Figure 2 within reference [1],

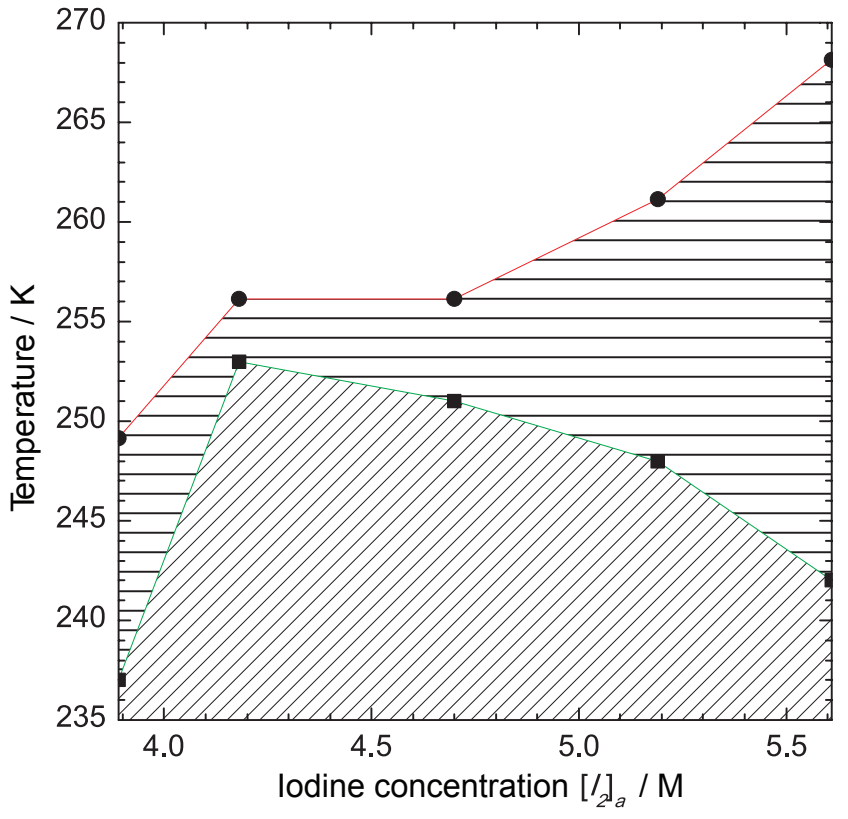

Figure 2. Phase diagram of PMII: Temperature versus iodine concentration $\left[\mathrm{I}_{2}\right]_{\mathrm{a}}$. Comparison of viscosity onset (dots) and dc conductivity cutoff (squares) temperatures versus $\left[\mathrm{I}_{2}\right]_{a}$ showing the viscoelatic phase for $\left[\mathrm{I}_{2}\right]_{\mathrm{a}}>3.9 \mathrm{M}$. The liquid (white), viscoelastic (lines) and crystalline (diagonal lines) phases are shown for decreasing temperatures at a cooling rate $<1 \mathrm{~K} \mathrm{~min}^{-1}$.

which is indicative of the appearance of higher polyiodides. Above $4.2 \mathrm{M}$, the viscoelastic temperature domain increases as $\left[\mathrm{I}_{2}\right]_{\mathrm{a}}{ }^{\mathrm{n}}$, the exponent $\mathrm{n}$ being 9.4 , reaching $\sim 26 \mathrm{~K}$ at $5.6 \mathrm{M}$. Even at the highest iodine concentration, where the viscoelastic phase exists from $268 \mathrm{~K}$ down to $242 \mathrm{~K}$, the $\mathrm{PMII} / \mathrm{I}_{2}$ system is capable of supporting both ionic conduction as well as Grotthuss-type conduction among higher polyiodides despite of the highly viscous nature of the melts.

From standard DSC measurements, we find that for concentrations less than $\left[\mathrm{I}_{2}\right]_{\mathrm{a}} \sim 3.9 \mathrm{M}$, the PMII/I $\mathrm{I}_{2}$ melts do not crystallize upon cooling, but enter a glassy state at $\sim 195 \mathrm{~K}$ and reform a liquid upon heating. For $\left[\mathrm{I}_{2}\right]_{\mathrm{a}}>3.9 \mathrm{M}$ and at a sufficiently slow cooling rate $<1 \mathrm{~K} / \mathrm{min}$, the $\mathrm{PMII} / \mathrm{I}_{2}$ melts crystallize at the temperature which coincides with the dc conductivity cutoff temperature. The temperature dependence of the dc conductivity reveals a hysteresis loop for $\left[\mathrm{I}_{2}\right]_{\mathrm{a}}>3.9 \mathrm{M}$ which is shown in Figure 3a for $\left[\mathrm{I}_{2}\right]_{\mathrm{a}}=5.61 \mathrm{M}$. The corresponding DSC measurements are shown in Figure $3 \mathrm{~b}$ for $\left[\mathrm{I}_{2}\right]_{\mathrm{a}}=5.61 \mathrm{M}$. Upon cooling, a sudden drop of the conductivity occurs at $\sim 242 \mathrm{~K}$ where the viscoelastic melt crystallizes, whereas upon reheating the crystalline phase, the dc conductivity starts to recover only at the melting point temperature of $\sim 260 \mathrm{~K}$. This is consistent with the notion that conduction is possible via physical diffusion and the Grotthuss mechanism in the viscoelastic phase, whereas both of these conduction mechanisms are impaired in the crystalline solid phase. This observation also excludes an electronic contribution to the conductivity other than the electrons which are involved in the Grotthuss bond exchange.

From Figure 2 and the subsequent discussion it follows that, adding $\mathrm{I}_{2}$ to PMII results in the formation of the viscoelastic 




Figure 3. a) Temperature dependent hysteresis of the dc conductivity for a PMII $/ \mathrm{I}_{2}$ mixture for a concentration $\left[\mathrm{I}_{2}\right]_{\mathrm{a}}=5.61 \mathrm{M}$. b) DSC data as a function of decreasing (scanning rate: $1 \mathrm{~K} \mathrm{~min}^{-1}$ ) and increasing (scanning rate: $2 \mathrm{~K} \mathrm{~min}^{-1}$ ) temperature for $\left[\mathrm{I}_{2}\right]_{\mathrm{a}}=5.61 \mathrm{M}$. Cooling (scanning rate: $1 \mathrm{~K} \mathrm{~min}^{-1}$ ), heating (scanning rate: $2 \mathrm{~K} \mathrm{~min}^{-1}$ ). b) The liquid, viscoelastic and crystalline phases are indicated on the figure for decreasing temperatures. The viscosity onset and dc conductivity cutoff are indicated by arrows. For increasing temperatures, the crystalline phase dominates until melting sets in at $\sim 260 \mathrm{~K}$.))

phase for $\left[\mathrm{I}_{2}\right]_{\mathrm{a}} \geq 3.9 \mathrm{M}$ below $T_{\text {onset }}$ where the conductivity changes smoothly and the molecular transport is essentially unaffected by the huge increase in viscosity (Figure 1). The threshold concentration $3.9 \mathrm{M}$ corresponds to $46 \mathrm{wt} \%$ or $25 \%$ volume fraction of $\mathrm{I}_{2}$ in PMII (5.6 M: $59 \mathrm{wt} \%$ or $37 \%$ volume fraction). This high $\mathrm{I}_{2}$ concentration implies a densely-packed porous polyiodide medium. By contrast, the polymer weight content of a gel with a rather dilute rigid three-dimensional network based on polymer-polymer associations is typically around 1 wt\%. ${ }^{[16]}$ Fast diffusion at high viscosities observed in the $\mathrm{PMII} / \mathrm{I}_{2}$ systems, for $\left[\mathrm{I}_{2}\right]_{\mathrm{a}} \geq 3.9 \mathrm{M}$, may be closer to surfactant systems in this respect. In the surfactant field there are many examples of the simultaneous occurrence of high viscosity and high molecular mobility also at high concentrations. One case is that of cubic liquid crystals, which are extremely viscous and more solid-like. ${ }^{[17]}$ For surfactants forming spherical micelles the viscosity increases by several orders of magnitude at a well-defined concentration. This can easily occur at surfactant volume fractions of the order of $40 \%$ and is due to strong micelle-micelle interactions leading to the crystallization and formation of a cubic liquid crystalline phase. ${ }^{[18]}$ The molecular transport is essentially unaffected by the huge increase in viscosity. If a compound, water and/or surfactant, forms connected structures its diffusivity is high. Water diffusion is not much slower than in neat water for many solid-like cubic phases and for bicontinuous phases surfactant diffusion is high. ${ }^{[19,20]}$

Previously it was found that incorporating the redox couple $\mathrm{I}^{-} / \mathrm{I}_{3}^{-}$and higher polyidides into existing gel electrolytes by adding iodine increases the conductivity, which was attributed to Grotthuss conduction. ${ }^{[21,22]}$ However, by adding iodine to the ionic liquid PMII we found that for $\left[\mathrm{I}_{2}\right]_{\mathrm{a}} \geq 3.9 \mathrm{M}$ a viscoelastic phase forms below $T_{\text {onset }}$ without the presence of any other gelling agent than the polyiodides themselves. Importantly, just above this same concentration the dc conductivity (see Figure 3b) increases dramatically due to Grotthuss conduction among the higher polyiodides. This coincidence underlines the major influence of the higher polyiodides in determining the thermodynamic and transport properties together with the high iodine/iodide packing density which enhances the Grotthuss mechanism by reducing the distance between the iodide/polyiodide species involved in the bond exchange. The increase of the liquid-viscoelastic transition temperature for increasing iodine concentration is furthermore consistent with the increasing packing density. In addition, the conductivity decreases for decreasing temperatures (Figure 1b). Based on these observations we attribute the gelation to be due to loss of mobility of the highly packed polyiodides as the temperature is decreased.

The rise in the room temperature conductivity of the PMII melts for $\left[\mathrm{I}_{2}\right]_{\mathrm{a}} \sim 5.61 \mathrm{M}$ compared to $\left[\mathrm{I}_{2}\right]_{\mathrm{a}} \sim 0.05 \mathrm{M}$ of more than 1 order of magnitude is linked to the increased Grotthuss conduction among higher polyiodides and the high iodine/ polyiodide packing density. For decreasing temperatures, this rise increases steadily to more than two orders of magnitude in the viscoelastic phase, implying a substantial improvement in the conduction of the PMII melts at high $\mathrm{I}_{2}$ concentrations and reduced temperatures compared to merely Grotthuss conduction in the $\mathrm{I}^{-} / \mathrm{I}_{3}{ }^{-}$redox couple below $\left[\mathrm{I}_{2}\right]_{\mathrm{a}} \sim 3.9 \mathrm{M}$. Conduction in the viscoelastic phase is demonstrated stable over at least the course of a day.

In the context of applications, the extraordinary performance of the PMII melts at high concentrations in terms of conductivity, particularly at reduced temperatures, is attractive. The enhanced performance at high concentrations $\left(\left[\mathrm{I}_{2}\right]_{\mathrm{a}}>3.9 \mathrm{M}\right)$ is hard to reach for PMII electrolytes in dye sensitized solar cells which are optimally doped at $\left[\mathrm{I}_{2}\right]_{\mathrm{a}} \sim 0.5 \mathrm{M} .{ }^{[23]}$ High $\mathrm{I}_{2}$ concentrations cause increased absorbance of the sunlight necessitating a compromise between transparency and conductivity in the PMII electrolyte. This compromise may be circumvented by reducing the spacer thickness between photo anode and counter electrode in order to reduce the light absorption. ${ }^{[24]}$ Such a dyesensitized solar cell with a high $\mathrm{I}_{2}$ concentration may display improved performance at reduced temperatures in the viscoelastic phase and may thus indicate a new avenue of research to be explored.

In conclusion, we have discovered that cooling of polyiodidecontaining PMII melts results in the formation of a viscoelastic phase for $\left[\mathrm{I}_{2}\right]_{\mathrm{a}}>3.9 \mathrm{M}$, which maintains a high conductivity through Grotthuss bond exchange and ionic conduction, despite of its very high viscosity. These novel results are important for the fundamental understanding of conduction in molten salts and quasi solid state electrolytes for applications where ionic liquids are used as charge-transporting media such as in batteries and dye-sensitized solar cells.

\section{Experimental Section}

PMII was prepared following a previously reported procedure. ${ }^{[25]}$ The $\mathrm{PMII} / \mathrm{I}_{2}$ mixtures were prepared by adding the calculated amount of 
iodine to the PMII, and the solution was then stirred with a magnetic stirring palette for two days to ensure that the iodine is completely dissolved. A Radiometer Analytical CDM210 conductivity meter was used for the conductivity measurements. A Radiometer CDC749 conductivity cell with a nominal cell constant of $1.70 \mathrm{~cm}^{-1}$ was calibrated with a $0.1 \mathrm{M} \mathrm{KCl}$ aqueous solution in preparation for the experiments. About $0.2 \mathrm{ml}$ of the $\mathrm{PMII} / \mathrm{I}_{2}$ mixture was introduced into a glass tube and solvated gases were removed using a slight vacuum of 0.6 Torr at room temperature for about 30 minutes. The conductivity cell and the $\mathrm{PMII} / \mathrm{I}_{2}$ mixture were then inserted into a glass tube in an Oxford cryostat with liquid nitrogen cooling for temperature control. At each temperature the $\mathrm{PMII} / \mathrm{I}_{2}$ mixture was allowed to equilibrate until the conductivity reading had stabilized, which would usually take between $30 \mathrm{~min}$ and $1 \mathrm{~h}$. The conductivity values were controlled by impedance spectroscopy using an Autolab Frequency Analyzer setup, which consists of an Autolab PGSTAT 30 and a frequency-response analyzer module combined with a thermostatic chamber capable of reaching $-40^{\circ} \mathrm{C}$. The viscosity measurements were carried out using a Rheometrics ARES Rheometer. All measurements were performed using parallel plates with a diameter of $25 \mathrm{~mm}$, a gap of $0.2 \mathrm{~mm}$, and a frequency of $1 \mathrm{~Hz}$. The DSC measurements were carried out using a TA Q100 apparatus. The NMR experiments were performed on a Bruker Avance-II spectrometer operating at a ${ }^{1} \mathrm{H}$ resonance frequency of $200.13 \mathrm{MHz}$. Pulsed field gradients were generated by a Bruker DIF-25 probe driven by a GREAT 40 amplifier. The sample temperature was controlled to an accuracy of $0.5^{\circ} \mathrm{C}$. The self-diffusion of $\mathrm{PMI}^{+}$was monitored by following the ${ }^{1} \mathrm{H}$ NMR signal in a pulsed gradient spin echo experiment ${ }^{[26-28]}$ using a gradient pulse length $\delta=4.2 \mathrm{~ms}$, time between onset of gradient pulses $\Delta=24.4 \mathrm{~ms}$, and gradient strength $G$ incremented from 1 to $100 \%$ of the maximum value $9.6 \mathrm{~T} / \mathrm{m}$ in 16 logarithmically spaced steps. The selfdiffusion coefficient $D$ was evaluated by fitting

$I=I_{0} \exp \left[\gamma^{2} G^{2} \delta^{2}\left(\begin{array}{ll}\Delta & \delta / 3\end{array}\right) D\right]$

to the experimental signal intensities $I$. In Equation $1, I_{0}$ is the signal intensity at zero gradient strength and $\gamma$ is the magnetogyric ratio $\left(2.675 \cdot 10^{8} \mathrm{rad} \mathrm{T}^{-1} \mathrm{~s}^{-1}\right.$ for $\left.{ }^{7} \mathrm{H}\right)$. Monoexponential signal decay was observed for all concentrations and temperatures indicating chemical exchange between the ion-paired and dissociated forms of PMII (PMII $\leftrightarrows \mathrm{PMI}^{+}+\mathrm{I}^{-}$) on a time scale much shorter than the 20 ms observational time scale of the NMR experiment.

\section{Supporting Information}

Supporting Information is available from the Wiley Online Library or from the author.

\section{Acknowledgements}

We thank Guido Rothenberger, Paul Dyson, Véronique Michaud and Christoper Plummer for valuable discussions or technical assistance. Work at EPFL was supported by the Swiss National Science Foundation and the Marie Curie Reintegration Grant MIRG-CT-2005-014868. Work at LU was supported by the Swedish Research Council through the Linnaeus Center of Excellence on Organizing Molecular Matter.

Received: November 3, 2011

Published online: January 3, 2012

[1] V. K. Thorsmølle, G. Rothenberger, D. Topgaard, J. C. Brauer, D.-B. Kuang, S. M. Zakeeruddin, B. Lindman, M. Grätzel, J.-E. Moser, ChemPhysChem 2011, 12, 145.

[2] M. Grätzel, Nature 2001, 414, 338.

[3] C. A. Angel, W. Xu, Science 2003, 302, 422.

[4] S. Seki, Y. Kobayashi, H. Miyashiro, Y. Ohno, A. Usami, Y. Mita, M. Watanabe, N. Terada, Chem. Commun. 2006, 544.

[5] C. Ye, W. Liu, Y. Chen, L. Yu, Chem. Commun. 2001, 2244.

[6] Ionic Liquids in Synthesis, (Eds: P. Wasserscheid, T. Welton), Wiley-VCH Verlag, Weinheim, 2008

[7] B. Lindman, G. Karlström, L. Stigsson, J. Mol. Liq. 2010, 156, 76

[8] R. Kawano, M. Watanabe, Chem. Commun. 2003, 330.

[9] R. Kawano, M. Watanabe, Chem. Commun. 2005, 2107.

[10] Y. Bai, Y. Cao, J. Zhang, M. Wang, R. Li, P. Wang, S. M. Zakeeruddin, M. Grätzel, Nat. Mater. 2008, 7, 626.

[11] N. Papageorgiou, Y.Athanassov, M.Armand, P. Bonhôte, H. Pettersson, A. Azam, M. Grätzel, J. Electrochem. Soc. 1996, 143, 3099.

[12] W. Kubo, T. Kitamura, K. Hanabusa, Y. Wada, S. Yanagida, Chem. Commun. 2002, 374.

[13] D. Kuang, P. Wang, S. Ito, S. M. Zakeeruddin, M. Grätzel, J. Am. Chem. Soc. 2006, 128, 2732.

[14] S. Zhang, K. H. Lee, C. D. Frisbie, T. P. Lodge, Macromolecules 2011, 44, 940.

[15] K. Ueno, K. Hata, T. Katakabe, M. Kondoh, M. Watanabe, J. Phys. Chem. B 2008, 112, 9013.

[16] Polymer Gels: Fundamentals and Applications, ACS Symposiumseries 833 (Eds: H. B. Bohidar, P. Dubin, Y. Osada), American Chemical Society, Washington DC, 2003.

[17] T. Enomoto, S. Kanematsu, K. Tsunashima, K. Matsumoto, R. Hagiwara, Phys. Chem. Chem. Phys. 2011, 13, 12536.

[18] T. Bull, B. Lindman, Mol. Cryst. Liquid Cryst. 1975, 28, 155.

[19] Bicontinuous Liquid Crystals, (Eds: M. L. Lynch, P. T. Spicer), CRC Press, Boca Raton (FL), 2005

[20] A. E. Frise, T. Ichikawa, M. Yoshio, H. Ohno, S. V. Dvinskikh, T. Kato, I. Furó, Chem. Commun. 2010, 46, 728.

[21] W. Kubo, K. Murakoshi, T. Kitamura, S. Yoshida, M. Haruki, K. Hanabusa, S. Shirai, Y. Wada, S. Yanagida, J. Phys. Chem. B 2001, 105, 12809.

[22] V. Z. Huo, S. Dai, C. Zhang, F. Kong, X. Fang, L. Guo, W. Liu, L. Hu, X. Pan, K. Wang, J. Phys. Chem. B 2008, 112, 12927.

[23] S. M. Zakeeruddin, M. Grätzel, Adv. Funct. Mater. 2009, 19, 2187.

[24] D. Friedrich, M. Kunst, J. Phys. Chem. C 2011, 115, 16657.

[25] P. Bonhôte, A.-P. Dias, N. Papageorgiou, M. Armand, K. Kalyanasundaram, M. Grätzel, Inorg. Chem. 1996, 35, 1168.

[26] P. Stilbs, Prog. Nucl. Magn. Reson. Spectrosc. 1987, $19,1$.

[27] W. S. Price, Concepts Magn. Reson. 1997, 9, 299.

[28] C. S. Johnson Jr., Prog. Nucl. Magn. Reson. Spectrosc. 1999, 34, 203. 


\section{ADVANCED}

Supporting Information

for Adv. Mater., DOI: 10.1002/adma.201104230

Conduction Through Viscoelastic Phase in a Redox-Active Ionic Liquid at Reduced Temperatures

Verner K. Thorsmølle, * Daniel Topgaard, Jan C. Brauer, Shaik M. Zakeeruddin, Björn Lindman, Michael Grätzel, and Jacques-E. Moser 


\section{Supporting Information}

\section{ADANACEPS
MATERRALIS}

\section{Conduction through Viscoelastic Phase in a Redox-}

\section{Active Ionic Liquid at Reduced Temperatures}

Verner K. Thorsmølle ${ }^{1}$, Daniel Topgaard $^{2}$, Jan C. Brauer ${ }^{1}$, Shaik M. Zakeeruddin $^{1}$, Björn Lindman ${ }^{2,3}$, Michael Grätzel ${ }^{1}$, Jacques-E. Moser ${ }^{1}$

${ }^{1}$ École Polytechnique Fédérale de Lausanne, Institute of Chemical Sciences and Engineering, CH-1015 Lausanne, Switzerland.

${ }^{2}$ Lund University, Department of Physical Chemistry 1, SE-22100 Lund, Sweden.

${ }^{3}$ Departamento de Quimica, Universidade de Coimbra Rua Larga, 3004-535-Coimbra, Portugal.

*e-mail: verner.thorsmolle@epfl.ch

\section{Contents}

Section S1. Methods .......................................................................................................... 2

Section S2. Viscosity measurements .........................................................................

Section S3. Differential scanning calorimetry measurements ............................... $\quad 7$

Section S4. Supporting references ................................................................................... 9 


\section{Section S1. Methods}

\section{ADNANEDS
MAATRRALIS}

Preparation of $\boldsymbol{P M I I}$ samples. The ionic liquid, 1-propyl-3-methylimidazolium iodide (PMII), was prepared according to the procedure reported in Ref. [1]. The $P M I I / I_{2}$ mixtures were prepared by adding the calculated amount of iodine to the PMII, and the solution was then stirred with a magnetic stirring palette for two days to ensure that the iodine is completely dissolved.

Conductivity measurements. A Radiometer Analytical CDM210 conductivity meter was used for the conductivity measurements. A Radiometer CDC749 conductivity cell with a nominal cell constant of $1.70 \mathrm{~cm}^{-1}$ was calibrated with a $0.1 \mathrm{M} \mathrm{KCl}$ aqueous solution in preparation for the experiments. About $0.2 \mathrm{ml}$ of the $P M I I / I_{2}$ mixture was introduced into a glass tube and solvated gases were removed using a slight vacuum of 0.6 Torr at room temperature for about 30 minutes. The conductivity cell and the $P M I I / I_{2}$ mixture were then inserted into a glass tube in an Oxford cryostat with liquid nitrogen cooling for temperature control. At each temperature the $P M I I / I_{2}$ mixture was allowed to equilibrate until the conductivity reading had stabilized, which would usually take between 30 minutes and 1 hour. The conductivity values were controlled by impedance spectroscopy using an Autolab Frequency Analyzer setup, which consists of an Autolab PGSTAT 30 and a frequencyresponse analyzer module combined with a thermostatic chamber capable of reaching $-40{ }^{\circ} \mathrm{C}$.

Viscosity measurements. The viscosity measurements were carried out using a Rheometrics ARES Rheometer. All measurements were performed using parallel plates with a diameter of $25 \mathrm{~mm}$, a gap of $0.2 \mathrm{~mm}$, and a frequency of $1 \mathrm{~Hz}$.

Differential scanning calorimetry measurements. The differential scanning calorimetry (DSC) measurements were carried out using a TA Q100 apparatus.

Nuclear magnetic resonance diffusivity measurements. NMR experiments were performed on a Bruker Avance-II spectrometer operating at a ${ }^{1} \mathrm{H}$ resonance frequency of $200.13 \mathrm{MHz}$. 
Pulsed field gradients were generated by a Bruker DIF-25 probe driven by a GREAT 40

\section{ADVANCED} amplifier. The sample temperature was controlled to an accuracy of $0.5^{\circ} \mathrm{C}$. The self-diffusion of $\mathrm{PMI}^{+}$was monitored by following the ${ }^{1} \mathrm{H}$ NMR signal in a pulsed gradient spin echo experiment $^{[2-4]}$ using a gradient pulse length $\delta=4.2 \mathrm{~ms}$, time between onset of gradient pulses $\Delta=24.4 \mathrm{~ms}$, and gradient strength $G$ incremented from 1 to $100 \%$ of the maximum value 9.6 $\mathrm{T} / \mathrm{m}$ in 16 logarithmically spaced steps. The self-diffusion coefficient $D$ was evaluated by fitting

$$
I=I_{0} \exp \left[-\gamma^{2} G^{2} \delta^{2}(\Delta-\delta / 3) D\right]
$$

to the experimental signal intensities $I$. In equation (2), $I_{0}$ is the signal intensity at zero gradient strength and $\gamma$ is the magnetogyric ratio $\left(2.675 \cdot 10^{8} \operatorname{radT}^{-1} \mathrm{~s}^{-1}\right.$ for $\left.{ }^{1} \mathrm{H}\right)$.

Monoexponential signal decay was observed for all concentrations and temperatures indicating chemical exchange between the IP and DIS forms of PMII on a time scale much shorter than the $20 \mathrm{~ms}$ observational time scale of the NMR experiment. 


\section{Section S2. Viscosity measurements}

\section{ADVANCED}

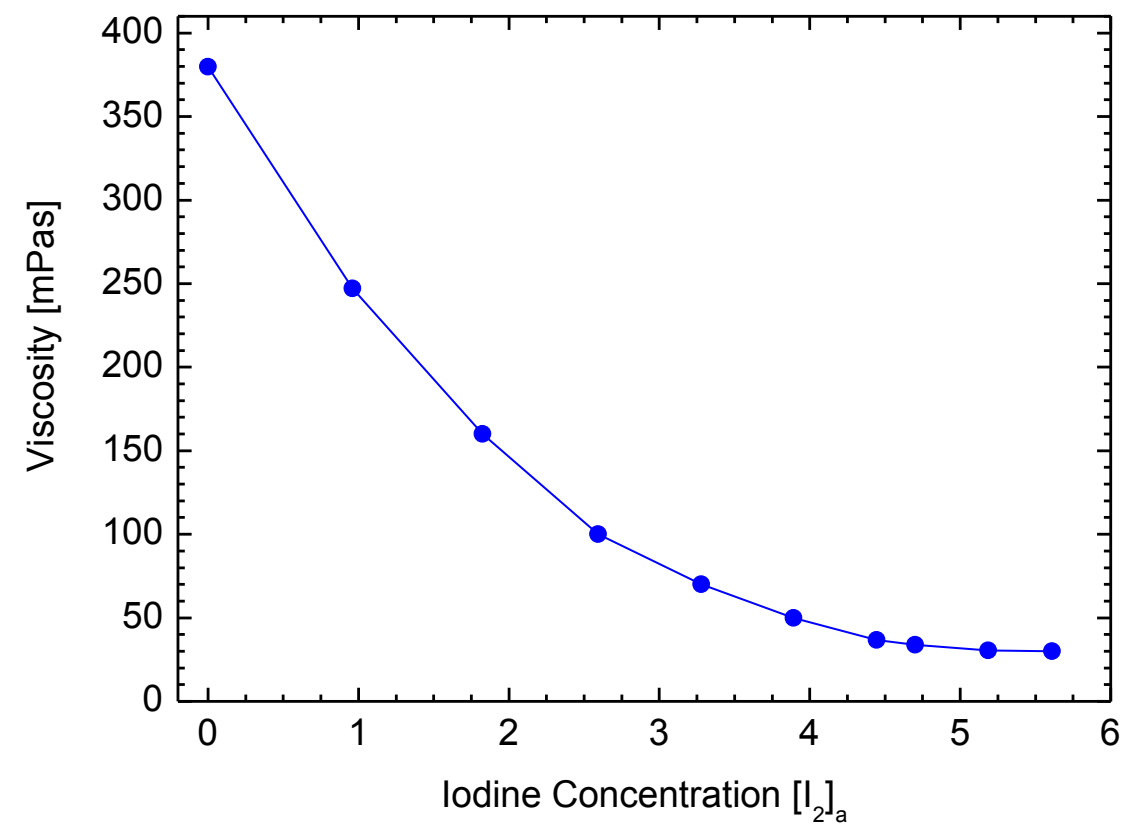

Figure S1. Measured viscosity versus iodine concentration $\left[I_{2}\right]_{a}$ at room temperature $\left(23.7^{\circ} \mathrm{C}\right)$.

The viscosity of $P M I I$ as a function of iodine concentration at room temperature is shown in Fig. S1.

Figure $\mathrm{S} 2$ shows a dynamic viscosity measurement of the $P M I I / I_{2}$ mixture as a function of temperature for an iodine concentration $\left[I_{2}\right]_{a}=4.18 \mathrm{M}$. Here the storage modulus $\mathrm{G}^{\prime}$ and the loss modulus G" represent the elastic and the viscous contributions to the dynamic shear modulus G, respectively. G” $>G^{\prime}$ is characteristic of a liquid phase which is observed for temperatures higher than the onset temperature of $\sim 256 \mathrm{~K}$. However, G' $>$ G' below the onset temperature of the sudden viscosity increase reveals a viscoelastic behaviour. Similar behaviour is observed for all mixtures for concentrations greater than $\left[I_{2}\right]_{a} \sim 3.9 \mathrm{M}$. Many viscoelastic materials like those based on surfactants or polymers are characterized by fast diffusion of small molecules and rapid conformational changes. ${ }^{[5]}$ 


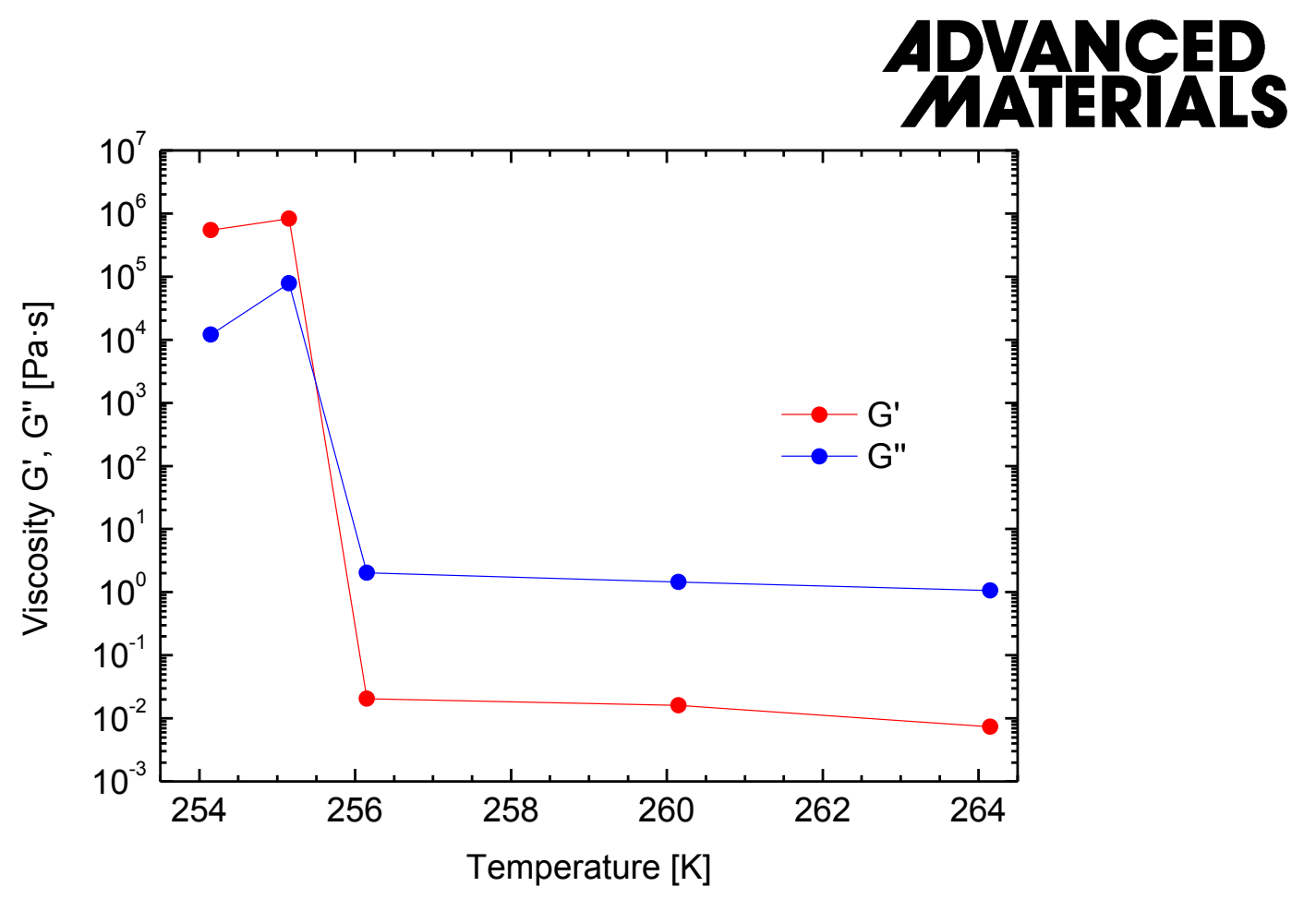

Figure S2. Dynamic viscoelastic behaviour of the $P M I I / I_{2}$ mixture for $\left[I_{2}\right]_{a}=4.18 \mathrm{M}$ close to the liquid-viscoelastic transition. G' and G" represent the elastic and viscous contributions, respectively.

\section{Section S3. Differential scanning calorimetry measurements}

Figure S3 shows DSC measurements of various concentrations $\left[I_{2}\right]_{a}$ of $P M I I / I_{2}$ mixtures for increasing temperatures and a scanning rate of $20 \mathrm{~K} / \mathrm{min}$. (DSC measurements for decreasing temperatures are nearly featureless and not shown in Fig. S2 for clarity). For concentrations less than $\left[I_{2}\right]_{a} \sim 3.9 \mathrm{M}$, the PMII melts do not crystallize, but enter a glassy state at $\sim 195 \mathrm{~K}$ and reforms a liquid upon heating. For $\left[I_{2}\right]_{a}>3.9 \mathrm{M}$, the PMII melts are likewise characterized by a glass transition at $\sim 195 \mathrm{~K}$, but upon heating they pass from the glass to a subcooled liquid phase from which a cold crystallization occurs at $\sim 235 \mathrm{~K}$ followed by melting at $\sim 265 \mathrm{~K}$. Both of these behaviours have previously been observed in various imidazolium-based ionic liquids without iodine added. ${ }^{[6]}$ However, for $\left[I_{2}\right]_{a}>3.9 \mathrm{M}$ and at a sufficiently slow cooling rate $<1 \mathrm{~K} / \mathrm{min}$, the $P M I I$ melts enter a crystalline phase for decreasing temperatures which tends to override the above mentioned phases until they melt 
at higher temperatures. Figure S4 shows DSC data for $\left[I_{2}\right]_{a}=5.6 \mathrm{M}$ for decreasing

\section{ADVANCED}

temperatures (scanning rate: $1 \mathrm{~K} / \mathrm{min}$ ) and increasing temperatures (scanning rate: $2 \mathrm{~K} / \mathrm{min}$ ) with the different phases indicated.

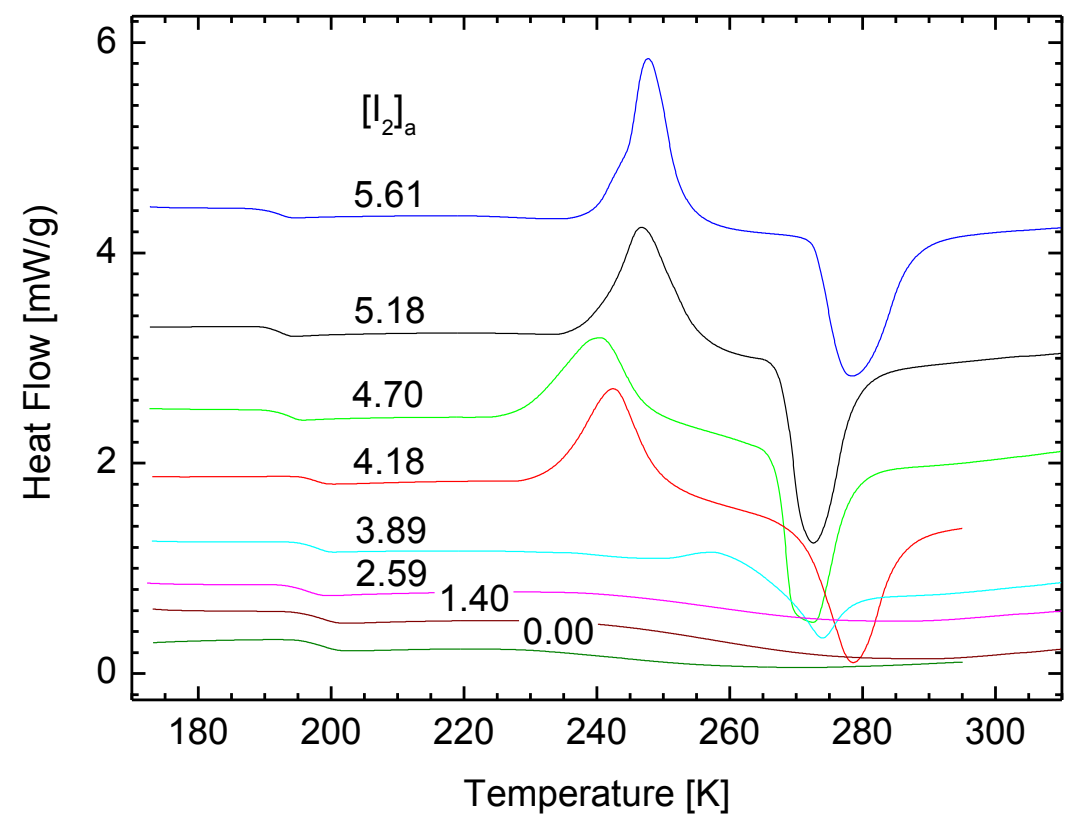

Figure S3. Differential scanning calorimetry data as a function of increasing temperature for various concentrations $\left[I_{2}\right]_{a}$ of $P M I I / I_{2}$ mixtures. Scanning rate: $20 \mathrm{~K} / \mathrm{min}$. The traces are displaced vertically for clarity.

The phase preceding the crystalline phase for decreasing temperatures is characterized by a viscoelastic behaviour with the viscosity increased by at least 6 orders of magnitude (See Figs. 1a, S2). Even at this high viscosity in the viscoelastic phase, ionic conduction and Grotthuss transport are sustained. 




Figure S4. Differential scanning calorimetry data as a function of decreasing (scanning rate: 1 $\mathrm{K} / \mathrm{min}$ ) and increasing (scanning rate: $2 \mathrm{~K} / \mathrm{min}$ ) temperature of a $P M I I / I_{2}$ mixture for a concentration $\left[I_{2}\right]_{a}=5.61 \mathrm{M}$. The various phases are indicated for decreasing and increasing temperatures.

\section{Section S4. Supporting references}

[1] P. Bonhôte, A.-P. Dias, N. Papageorgiou, M. Armand, K. Kalyanasundaram, M. Grätzel, Inorg. Chem. 1996, 35, 1168.

[2] P. Stilbs, Prog. Nucl. Magn. Reson. Spectrosc. 1987, 19, 1.

[3] W. S. Price, Concepts Magn. Reson. 1997, 9, 299.

[4] C. S. Johnson Jr., Prog. Nucl. Magn. Reson. Spectrosc. 1999, 34, 203.6. S. A. Baeurle, A. Hotta, A. A. Gusev, Polymer 2006, 47, 6243.

[5] S. A. Baeurle, A. Hotta, A. A. Gusev, Polymer 2006, 47, 6243.

[6] C. P. Fredlake, J. M. Crosthwaite, D. G. Hert, S. N. V. K. Aki, J. F. Brennecke, J. Chem. Eng. Data 2004, 49, 954. 